\title{
Results from the BJD survey on readership views towards clinical practice guidelines
}

DOI:

10.1111/bjd.18960

\section{Document Version}

Accepted author manuscript

Link to publication record in Manchester Research Explorer

\section{Citation for published version (APA):}

Yiu, Z. Z. N., Jabbar-Lopez, Z. K., Ahmed, S., Mohd Mustapa, M. F., Chi, C-C., \& Flohr, C. (2020). Results from the BJD survey on readership views towards clinical practice guidelines. The British journal of dermatology. https://doi.org/10.1111/bjd.18960

\section{Published in:}

The British journal of dermatology

\section{Citing this paper}

Please note that where the full-text provided on Manchester Research Explorer is the Author Accepted Manuscript or Proof version this may differ from the final Published version. If citing, it is advised that you check and use the publisher's definitive version.

\section{General rights}

Copyright and moral rights for the publications made accessible in the Research Explorer are retained by the authors and/or other copyright owners and it is a condition of accessing publications that users recognise and abide by the legal requirements associated with these rights.

\section{Takedown policy}

If you believe that this document breaches copyright please refer to the University of Manchester's Takedown Procedures [http://man.ac.uk/04Y6Bo] or contact uml.scholarlycommunications@manchester.ac.uk providing relevant details, so we can investigate your claim.

\section{OPEN ACCESS}


DR ZENAS ZEE NGAI YIU (Orcid ID : 0000-0002-1831-074X)

PROFESSOR CARSTEN FLOHR (Orcid ID : 0000-0003-4884-6286)

Article type : Research Letter

\section{Results from the BJD survey on readership views towards clinical practice guidelines}

Z. Z. N. Yiu, ${ }^{1}$ Z. K. Jabbar-Lopez, ${ }^{2,}{ }^{3}$ S. Ahmed, ${ }^{4}$ M. F. Mohd Mustapa, ${ }^{4}$ C.-C. Chi ${ }^{5,6}$ and C. Flohr ${ }^{2}$ Affiliations:

1. Centre for Dermatology Research, Salford Royal NHS Foundation Trust, The University of Manchester, Manchester Academic Health Science Centre, NIHR Manchester Biomedical Research Centre, Manchester, M13 9PT, UK

2. St John's Institute of Dermatology, King's College London and Guy's \& St Thomas' NHS Foundation Trust, London, SE1 9RT, UK

3. Galderma R\&D, Lausanne, Switzerland.

4. British Association of Dermatologists, London, W1T 5HQ, UK

5. Department of Dermatology, Chang Gung Memorial Hospital, Linkou, Taoyuan, Taiwan

6. College of Medicine, Chang Gung University, Taoyuan, Taiwan

Correspondence: Zenas Yiu

Email: zenas.yiu@manchester.ac.uk

This article has been accepted for publication and undergone full peer review but has not been through the copyediting, typesetting, pagination and proofreading process, which may lead to differences between this version and the Version of Record. Please cite this article as doi: $\underline{10.1111 / B J D .18960}$

This article is protected by copyright. All rights reserved 
Dear Editor,

The $B J D$ has been publishing clinical practice guidelines (CPG) in dermatology for more than 20 years. ${ }^{1-3}$ With the increasing adoption of gold-standard guideline development methodology and reporting checklists, such as the GRADE ${ }^{4}$ approach and the AGREE II toolkit, recent CPGs published in the $B J D$ are of high-quality and are highly accessed, with CPGs making up half of the top 10 downloaded $B J D$ articles in 2019. As a group of guideline developers and journal editors associated with the $B J D$, we were interested in how the readership perceives and uses CPGs. The objective of this study was to survey the BJD readership's demographics, utility of and attitudes towards CPGs.

An anonymous, cross-sectional electronic survey for healthcare professionals was conducted between May 2019 and January 2020. The survey was distributed to 7000 people listed as a BJD author through email via $B J D$ submission system. The survey was promoted on the $B J D$ social 
media platforms Facebook and Twitter, the Wiley online library BJD website, as well as to the British Association of Dermatologists membership through newsletters.

The questionnaire consisted of 2 sections and 21 questions. We selected eligible participants, being health care practitioners, with an introductory question. We also collected information about participants' age, sex, number of years' experience within dermatology, country of practice, as well as the frequency of access to the BJD for CPGs, and the preference of CPG type in the first section. Free-text sections were included for the final two questions. The second section consisted of 13 statements to which the respondents indicated their agreement or disagreement on a 5-point Likert scale (1 Strongly disagree, 5 Strongly agree). These statements identified the attitudes to CPGs, barriers to the use of CPGs and perceived reliability of CPGs that were based on a previous study ${ }^{6}$ and the 'Attitudes Towards Guidelines' scale. ${ }^{7}$ A final question elicited an overall suggestion for making CPGs more useful for daily clinical practice. We performed descriptive analyses of the data, and thematic analysis of the overall suggestions in the final question.

There were 1043 questionnaire responses ( $14.9 \%$ response rate), out of which 758 participants were eligible healthcare professionals. Most of the respondents were between 35 and 64 years of age $(n=542,71.5 \%)$, and over half were male $(n=432,57.0 \%)$. There was a median of 18.0 years of clinical dermatology experience (interquartile range [IQR] 10.0-27.0). There were respondents from 68 different countries, and there were 9 countries of origin which had more than 20 respondents: the Netherlands $(n=21)$, India $(n=24)$, France $(n=30)$, Japan $(n=38)$, Taiwan $(n=40)$, Italy $(n=47)$, Germany $(n=48)$, the US $(n=80)$ and the UK $(n=142)$.

Most respondents ( $n=552,72.8 \%$ ) had accessed the $B J D$ for a CPG within 6 months of the survey. A total of 33 respondents gave reasons for not accessing the BJD for CPGs, including getting CPGs from other sources; CPGs were behind the paywall; and CPGs were not applicable to the local population. The majority ( $n=614,81.0 \%$ ) of respondents found disease-based guidelines the most useful, compared to $(n=107,14.1 \%)$ for drug-utility guidelines. The remaining respondents found that both guideline types were equally helpful; that neither were useful; or that diagnostic and procedure-based guidelines were favourable instead ( $n=37,4.9 \%$ ).

There was an agreement to most statements assessing attitudes towards guidelines posed in section 2, with the mean Likert score above 4 or below 2 in 7 questions (Figure 1). There was a variety of opinion for two statements that related to attitudes towards CPG - "Guidelines oversimplify medical practice" (mean score 3.0, standard deviation [SD] 1.2), "Guidelines challenge the autonomy of care providers" $(3.1,1.2)$; and one for a barrier of use statement - 
"Guidelines are difficult to find if needed" (2.6, 1.2). Four main themes (succinctness of guidelines, better accessibility, more considerations for implementation, and more updates) were identified from the final question.

These results indicate that the global readership have a broadly positive attitude towards the reliability and utility of CPGs published in the BJD. The two statements with the highest divergence of opinion are indicative of the debate on and art of guideline implementation in medicine, with the mantra "Guidelines, not tramlines"8 elegantly summarising the balance needed between guideline recommendations adherence and clinical judgement for real-world implementation. The overall narrative identified CPG improvement could be achieved through more readily accessible and applicable recommendations at the bedside. The main limitation of this survey was the low estimated response rate.

In conclusion, guidelines published in the BJD are highly accessed and valued by the readership. Guidelines are well received by the readership if they adhere to gold-standard development and reporting standards; are succinct; accessible; have applicable implementation toolkits; and are up to date. 
Figure 1 - Stacked bar chart from section 2 of the questionnaire showing statements and response on a 5-point Likert scale of agreement (statements on the $y$-axis; \% of respondents on the x-axis). Responses below 4 on the Likert scale are placed to the left of the $x$-axis midpoint for clarity. The total length of each bar represents $100 \%$ of the respondents.

Guidelines are difficult to find if needed

Guideline author declarations of interest are not crucial

Guidelines are not useful in clinical work

Guidelines oversimplify medical practice

Guidelines challenge the autonomy of care providers

Guidelines useful as standard of care to audit against

It is important to have a lay summary of guidelines

Guidelines are based on scientific evidence

Guidelines implemenation tools are useful

Guideline funding should be explicit and publicly accessible

Guidelines can improve the quality of healthcare

Seeing the evidence underlying a recommendation is useful

Guideline development quality is important

Strongly disagree

$-100$

$-80$

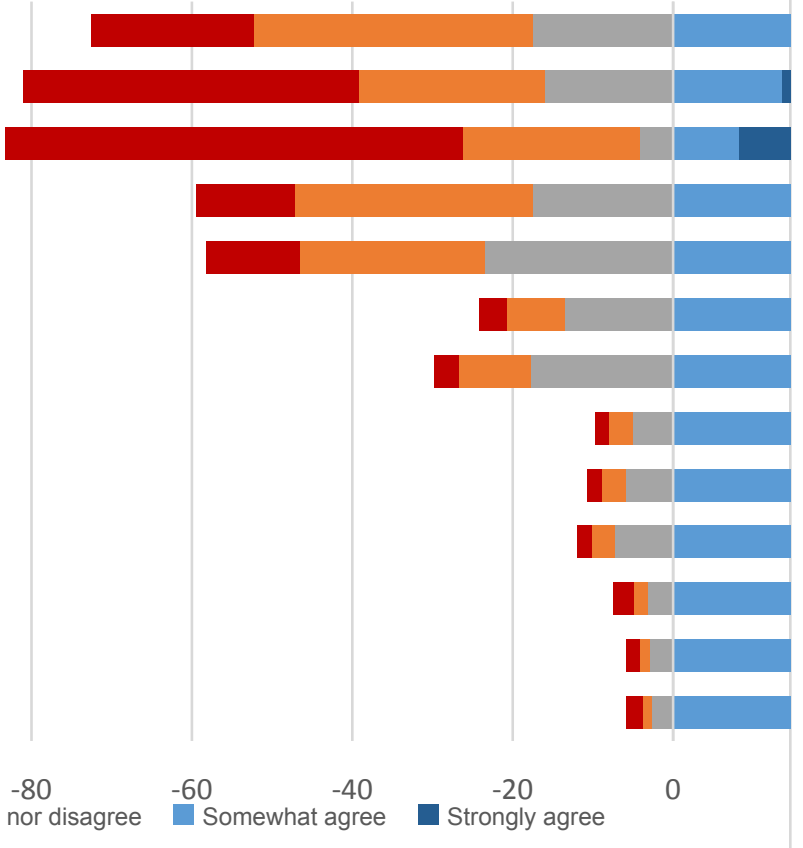

This article is protected by copyright. All rights reserved 


\section{References}

$1 \quad$ Griffiths CE. The british association of dermatologists guidelines for the management of skin disease. Br J Dermatol 1999; 141: 396-7.

2 Bell HK, Ormerod AD, Therapy BAD et al. Writing a British Association of Dermatologists clinical guideline: an update on the process and guidance for authors. Br J Dermatol 2009; 160: 725-8. Mohd Mustapa MF, Exton LS, Bell HK et al. Updated guidance for writing a British Association of Dermatologists clinical guideline: the adoption of the GRADE methodology 2016. Br J Dermatol 2017; 176: 44-51.

Guyatt GH, Oxman AD, Vist GE et al. GRADE: an emerging consensus on rating quality of evidence and strength of recommendations. BMJ 2008; 336: 924-6.

5 Brouwers MC, Kho ME, Browman GP et al. AGREE II: advancing guideline development, reporting and evaluation in health care. J Clin Epidemiol 2010; 63: 1308-11.

6 Wakkee M, Lugtenberg M, Spuls PI et al. Knowledge, attitudes and use of the guidelines for the treatment of moderate to severe plaque psoriasis among Dutch dermatologists. Br J Dermatol 2008; 159: 426-32.

7 Thorsen T, Mäkelä M, Dansk sygehus i. Changing professional practice : theory and practice of clinical guidelines implementation. 1999.

8 McCartney M. Margaret McCartney: Have we given guidelines too much power? BMJ 2014; 349: g6027.

Funding sources: ZZNY is funded by a National Institute for Health Research (NIHR) Academic Clinical Lectureship through the University of Manchester. ZJL is an employee of Galderma S.A..

Conflicts of interest: ZZNY, CF and CC have no conflicts to declare. SA and MFMM are employees of the BAD. 